\title{
Control-Oriented Modelling of a Wankel Rotary Engine: A Synthesis Approach of State Space and Neural Networks
}

DOI:

10.4271/2020-01-0253

\section{Document Version}

Final published version

Link to publication record in Manchester Research Explorer

\section{Citation for published version (APA):}

Chen, A. S., Vorraro, G., Turner, M., Islam, R., Herrmann, G., Burgess, S., Brace, C., Turner, J., \& Bailey, N.

(2020). Control-Oriented Modelling of a Wankel Rotary Engine: A Synthesis Approach of State Space and Neural Networks. In WCX SAE World Congress Experience 2020 https://doi.org/10.4271/2020-01-0253

\section{Published in:}

WCX SAE World Congress Experience 2020

\section{Citing this paper}

Please note that where the full-text provided on Manchester Research Explorer is the Author Accepted Manuscript or Proof version this may differ from the final Published version. If citing, it is advised that you check and use the publisher's definitive version.

\section{General rights}

Copyright and moral rights for the publications made accessible in the Research Explorer are retained by the authors and/or other copyright owners and it is a condition of accessing publications that users recognise and abide by the legal requirements associated with these rights.

\section{Takedown policy}

If you believe that this document breaches copyright please refer to the University of Manchester's Takedown Procedures [http://man.ac.uk/04Y6Bo] or contact uml.scholarlycommunications@manchester.ac.uk providing relevant details, so we can investigate your claim.

\section{OPEN ACCESS}




\title{
Control-Oriented Modelling of a Wankel Rotary Engine: A Synthesis Approach of State Space and Neural Networks
}

\author{
Anthony Siming Chen University of Bristol \\ Giovanni Vorraro, Matthew Turner, and Reza Islam University of Bath
}

Guido Herrmann University of Manchester

Stuart Burgess University of Bristol

Chris Brace and James Turner University of Bath

Nathan Bailey Advanced Innovative Engineering (UK) Ltd.

Citation: Chen, A.S., Vorraro, G., Turner, M., Islam, R. et al., "Control-Oriented Modelling of a Wankel Rotary Engine: A Synthesis Approach of State Space and Neural Networks," SAE Technical Paper 2020-01-0253, 2020, doi:10.4271/2020-01-0253.

\section{Abstract}

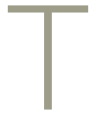

he use of Wankel rotary engines as a range extender has been recognised as an appealing method to enhance the performance of Hybrid Electric Vehicles (HEV). They are effective alternatives to conventional reciprocating piston engines due to their considerable merits such as lightness, compactness, and higher power-to-weight ratio. However, further improvements on Wankel engines in terms of fuel economy and emissions are still needed. The objective of this work is to investigate the engine modelling methodology that is particularly suitable for the theoretical studies on Wankel engine dynamics and new control development.

In this paper, control-oriented models are developed for a 225CS Wankel rotary engine produced by Advanced Innovative Engineering (AIE) UK Ltd. Through a synthesis approach that involves State Space (SS) principles and the artificial Neural Networks (NN), the Wankel engine models are derived by leveraging both first-principle knowledge and engine test data. We first re-investigate the classical physicsbased Mean Value Engine Model (MVEM). It consists of differential equations mixed with empirical static maps, which are inherently nonlinear and coupled. Therefore, we derive a SS formulation which introduces a compact control-oriented structure with low computational demand. It avoids the cumbersome structure of the MVEM and can further facilitate the advanced modern control design. On the other hand, via black-box system identification techniques, we compare the different $\mathrm{NN}$ architectures that are suitable for engine modelling using time-series test data: 1) the Multi-Layer Perceptron (MLP) feedforward network; 2) the Elman recurrent network; 3) the Nonlinear AutoRegressive with eXogenous inputs (NARX) recurrent network. The NN models overall tend to achieve higher accuracy than the MVEM and the SS model and do not require a priori knowledge of the underlying physics of the engine.

\section{Introduction}

y far the most important reasons for the limited use of the Wankel rotary engine are the fuel economy and emissions [1]. The high hydrocarbon emissions and poor fuel economy are generally believed to be caused by the unburnt air-fuel mixture leaking past the apex seals among chambers [2]. Moreover, the common Port Fuel Injection (PFI) configuration for the Wankel engine can result in typical "wall-wetting" phenomenon, where a considerable portion of fuel keeps condensing on and evaporating at the intake manifold wall as fuel puddles [ $\underline{3}$ ]. The fuel puddles heavily contribute to the air-fuel ratio excursion. The air-fuel ratio control is a critical task in order to assure a satisfactory efficiency of the three-way catalytic converters and to meet the emission requirement. An intuitive way to overcome this issue is to apply direct fuel injection (DFI), the feasibility of which was investigated in previous work [4]. On the other hand, the authors [ $[5]$ also proposed a novel nonlinear observerbased air-fuel ratio controller for the Wankel engine where the fuel puddle dynamics can be online estimated.

The modern Wankel engine finds use outside the automotive industries, e.g., aerospace, marine, auxiliary power units. In recent years, investigations have been made on the idea of incorporating a Wankel engine as a range extender for Hybrid Electric Vehicles (HEV) [6]. This motivates the work on the Wankel engine modelling and control with the objectives of 
improving the fuel economy and reducing the emissions for the Wankel engine. At the present time, control-oriented mathematical models that specifically describe the Wankel engine dynamics are lacking.

Engine modelling has been playing an important role in the engine development and optimisation process. Accurate and fast engine simulations could allow for rapid incorporation of new control design. The control development process can be significantly shortened when using efficient computational tools. High-fidelity model may reduce the hardware prototypes and development cost. Commercial software such as AVL BOOST offers a dedicated platform for modelling the Wankel engine dynamics as a one-dimensional Computational Fluid Dynamics (CFD) model [4]. The CFD models usually have high fidelity and requires a large amount of computational time. In the case of real-time control development, a physics-based Mean Value Engine Model (MVEM) developed by Hendricks $[\underline{7}, \underline{8}]$ is widely used with low-fidelity but fast running speed. Instead of cycle by cycle analysis, the MVEM presents the average response of multiple ignition cycles in the time domain. It was originally derived mainly for reciprocating engines and may not be able to directly apply to the Wankel rotary engine. Furthermore, the MVEM contains nonlinear differential equations mixed with empirical static maps and often has cumbersome structure. One way to overcome the complexity and to provide fast solution for control design is the linear State Space (SS) modelling. The SS model plays a central role in modern control theory [9] and have been commonly used as a framework for robust control, optimal control, etc. It can effectively deal with a Multi-Input, Multi-Output (MIMO) system such as engines. A linear SS model for engines was proposed in [10] for the application of linear quadratic control. The model was then generalised in [11] for internal combustion engines for control analysis. In the last decade, the artificial Neural Networks (NN) have been seen as an attractive approach for dynamic system modelling and control. There are many studies on the application of NN on engine modelling, e.g., $[\underline{12}, \underline{13}, \underline{14}, \underline{15}, \underline{16}, \underline{17}]$ therein. NN can be regarded as a black-box system identification approach that is conceptually simple, easy to use, and have excellent approximation properties.

In this paper, we first establish the MVEM for the Wankel engine. By properly selecting the state variables, a SS formulation is realised and then linearised around a nominal operating point. We then investigate different classes of $\mathrm{NN}$ for the Wankel engine modelling: 1) the Multi-Layer Perceptron (MLP) network; 2) the Elman network; 3) the Nonlinear AutoRegressive with eXogenous inputs (NARX) network. The comparison and analysis for the performance and complexity of the proposed models are presented in the end.

\section{Experimental Setup and Data Collection}

This section presents the experimental setup for the engine tests. The test data collected will be used later for the Wankel engine modelling and validation procedure.

\section{Experimental Setup}

The Wankel engine under investigation for dynamic modelling is a 225CS rotary engine, produced by Advanced Innovative Engineering (AIE) UK Ltd. It is a single-rotor, peripheral-port-injected, twin-spark engine and was previously configured to have a nominal peak power output of $30 \mathrm{~kW}$ for aerospace use on drones. Due to its high specific power output, there is a recent interest in using it as a range extender for HEV. Figure 1 shows an image of the Computeraided Design (CAD) model of the engine. Table 1 presents the fundamental engine geometry of the AIE 225CS Wankel rotary engine.

The engine experiments are carried out in an engine test cell at the Institute for Advanced Automotive Propulsion Systems (IAAPS) at the University of Bath. The test cell is equipped with an AC dynamometer for the assessment of the engine performance. The maximum nominal power and speed allowed from the $\mathrm{AC}$ motor is around $50 \mathrm{~kW}$ and $8500 \mathrm{RPM}$, respectively. The test facilities include a Sierra CP Test Automation System with the proprietary CADET software, which enables the dynamometer control and data acquisition via the transducers installed on the engine. The system can also collect data via the automotive standard Controller Area Network (CAN) bus, which can be compared online with the data from the Engine Control Unit (ECU). The ECU employed by AIE is an EM80 model produced by the project partner General Engine Management Systems (UK) Ltd (GEMS). It is online configurable when connected to the GEMS GWv4 proprietary software so that the user is able to control and monitor the engine parameters such as air-fuel ratio control, fly-by-wire throttle control.

\section{FIGURE 1 A CAD model of AIE (UK) Ltd 225CS Wankel} rotary engine with the intake and exhaust pipe installed [4].

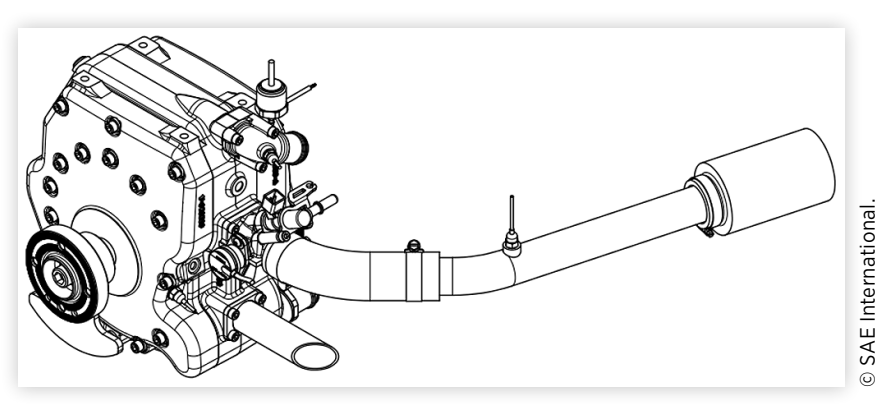

TABLE 1 The fundamental geometry of the AIE 225CS Wankel rotary engine.

\begin{tabular}{|c|c|}
\hline Deffinition & Value \\
\hline Generating Radius & $69.5[\mathrm{~mm}]$ \\
\hline Eccentricity & $11.6[\mathrm{~mm}]$ \\
\hline Offset/Equidistance & $2[\mathrm{~mm}]$ \\
\hline Width of Rotor Housing & $51.941[\mathrm{~mm}]$ \\
\hline Total Displacement & $225[\mathrm{cc}]$ \\
\hline Mass (excluding ancillaries) & $10[\mathrm{~kg}]$ \\
\hline Compression Ratio & 9.6:1 \\
\hline
\end{tabular}




\section{Data Collection}

To be able to calibrate the engine model (or to train the NN) and validate its fidelity, one needs to capture as much information as possible from the engine tests. The data collected should cover a broad engine operation range. We run the engine from $\sim 3500$ RPM to 6000 RPM, the throttle angle is swept from $\sim 20^{\circ}$ to $90^{\circ}$ (i.e., fully opening) for each fixed speed with the resolution of 500 RPM. Figure 2 shows the operation trajectories covered in the engine tests. The collected data including the throttle angle, the intake manifold pressure and temperature, the engine speed and torque, the air-fuel ratio are shown in Figure 3 . The sampling period of the signals is chosen as $0.02 \mathrm{~s}$.

FIGURE 2 Operating points collected during engine tests with the range: Engine speed 3500 6500 [RPM]; Engine torque $10 \sim 35[\mathrm{Nm}]$.

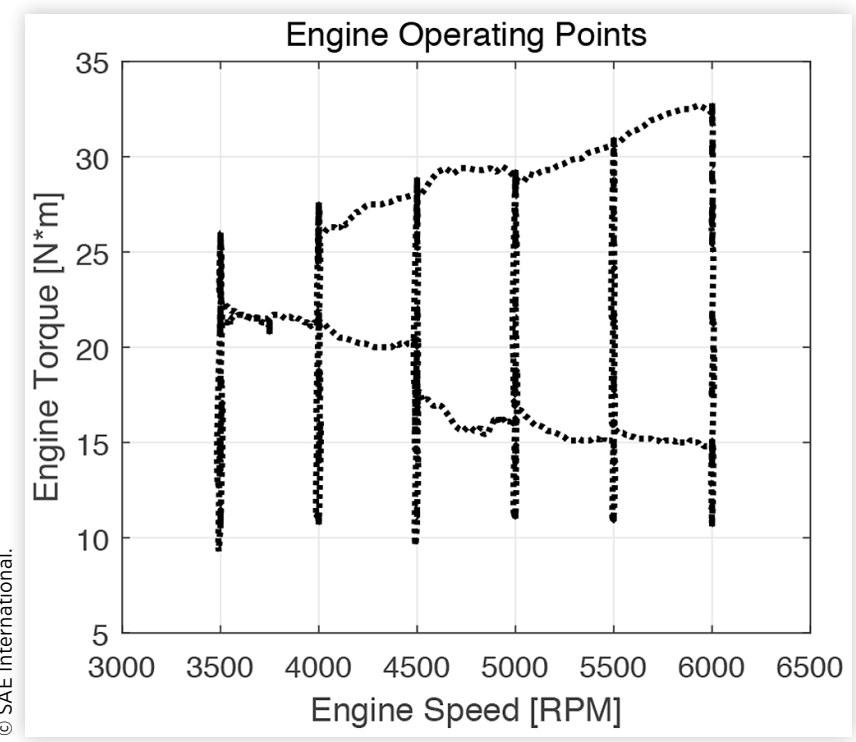

FIGURE 3 Engine test data collected for modelling and validation. The data traces start at the time $500 \mathrm{~s}$ after warming up the engine.
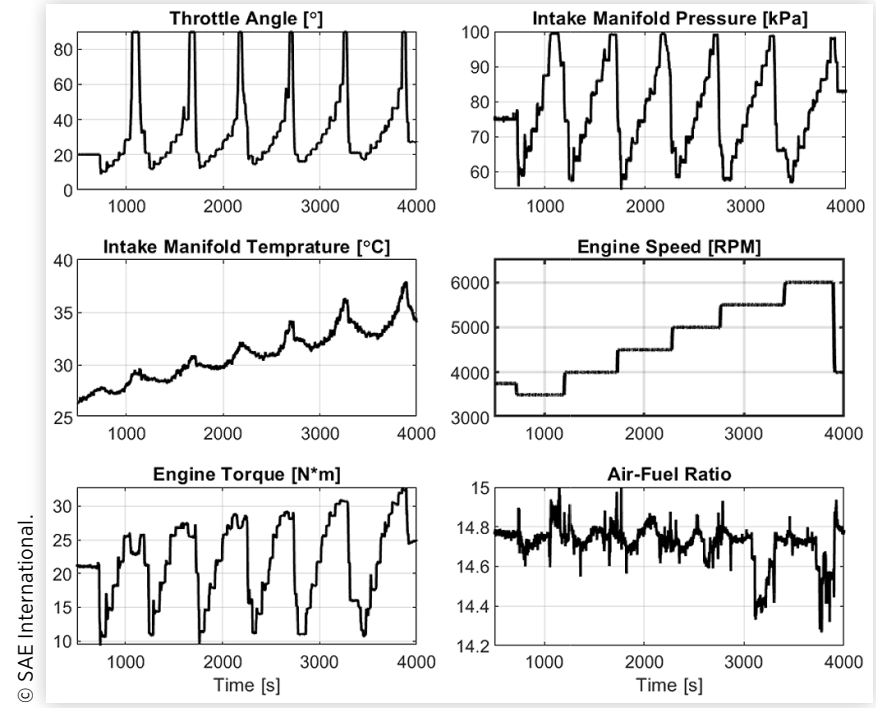

\section{Mean Value Engine Model}

The foundation of this section is the nonlinear Mean Value Engine Model (MVEM) developed by Hendricks $[\underline{7}, \underline{8}]$ and our previous work $[\underline{5}, \underline{18}]$. There is a paucity of literature on dynamic modelling of the rotary engine. Sparse studies $[2, \underline{19}$, 20] on Wankel engine modelling were around the early 1980s. The MVEM model developed by Hendricks was suggested mainly for reciprocating engines and has been widely used in engine control development. However, it is feasible to model the Wankel engine using an equivalent reciprocating MVEM since it operates with the same Otto cycle. A single-rotor Wankel engine is equivalent to a two-cylinder four-stroke reciprocating engine. Figure 4 shows the correspondence of the intake, compression, expansion and exhaust phases of the two types of engines.

In this section, we formulate an MVEM particularly for the AIE 225CS Wankel rotary engine. The model contains comprehensive representations of the air induction dynamics, the fuel injection dynamics, the engine torque generation (combustion), and the eccentric shaft rotation dynamics. The model should a) be fast enough to be used in control design process; b) be able to describe the influence of control inputs on the engine outputs in the time domain (instead of the cycle/ angle domain).

\section{Air Induction Model}

The air induction model describes the air mass flow from the throttle body through the intake manifold. It involves important engine variables such as the intake manifold pressure $p_{m}$, the intake manifold temperature $T_{m}$, and the air mass flow rate $\dot{m}_{a}$.

Throttle Body Model Assuming one-dimensional, steady, isentropic compressible flow of an ideal gas, the air mass flow rate $\dot{m}_{a t}$ passing the throttle can be described as

$$
\dot{m}_{a t}\left(\alpha, p_{m}\right)=m_{a t 1} \frac{p_{a}}{\sqrt{T_{a}}} T C(\alpha) P R I\left(p_{m}\right)+m_{a t 0}
$$

FIGURE 4 Comparison of Otto cycles between the Wankel rotary engine (above) and reciprocating engine (below). The correspondence of the four strokes (i.e., intake, compression, combustion, and exhaust) between both designs is presented [Modified from [4]].
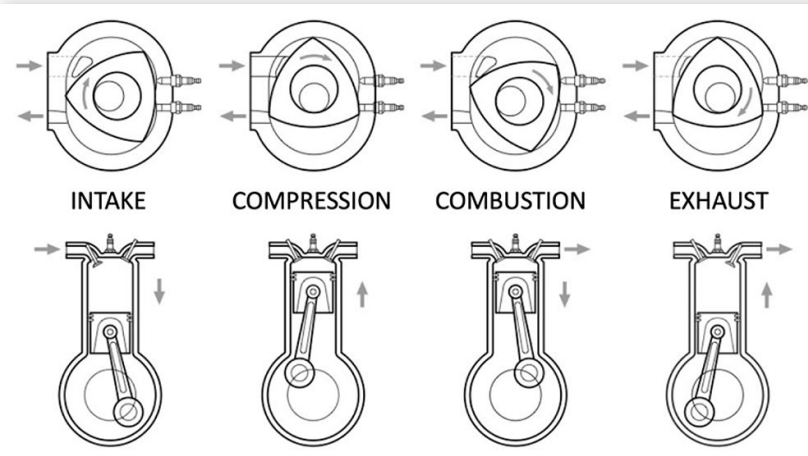

EXHAUST
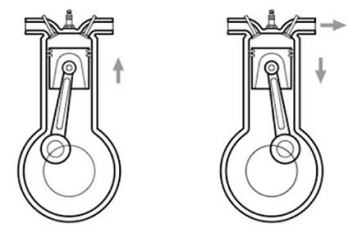

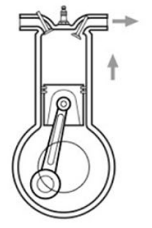


where $m_{a t 1}=c_{t} \frac{\pi}{4} D^{2} \sqrt{2 \kappa / R(\kappa-1)}$ is a physical constant related to the ratio of the specific heat constant $\kappa$, the ideal gas constant $R$, the flow coefficient $c_{t}$ and the diameter $D$ of throttle body throat; $m_{a t 0}$ is a fitting constant; $p_{a}$ and $T_{a}$ are the ambient pressure and temperature, respectively; $T C(\alpha)=1-\cos \left(\alpha-\alpha_{0}\right)$ denotes the throttle characteristics function of the throttle plate angle $\alpha$ and the leakage constant $\alpha_{0}$, which approximates the effective throttle area; $P R I\left(p_{m}\right)$ refers to the pressure ratio influence from the choke/sonic compressible flow, which can be expressed as

$$
\operatorname{PRI}\left(p_{m}\right)=\left\{\begin{array}{cc}
\sqrt{1-\left(\frac{p_{r}-p_{c}}{1-p_{c}}\right)^{2}} & \text { if } p_{r} \geq p_{c}(\text { choked }) \\
1 & \text { if } p_{r} \leq p_{c}(\text { sonic })
\end{array}\right\}
$$

where $p_{c}$ is the threshold point and $p_{r}=p_{m} / p_{a}$ is the ratio of the intake manifold pressure $p_{m}$ to the ambient pressure $p_{a}$.

Intake Manifold Model Neglecting the heat transfer, an adiabatic model of the air-filling dynamics in the intake manifold can be given as

$$
\begin{gathered}
\dot{p}_{m}=\frac{\kappa R}{V_{m}}\left(\dot{m}_{a t} T_{a}-\dot{m}_{a} T_{m}\right) \\
\dot{T}_{m}=\frac{R T_{m}}{p_{m} V_{m}}\left[\dot{m}_{a t}\left(T_{a} \kappa-T_{m}\right)-\dot{m}_{a}\left(T_{m} \kappa-T_{m}\right)\right]
\end{gathered}
$$

where $T_{m}$ is the manifold temperature and $V_{m}$ is the manifold volume. Then the port air mass flow rate $\dot{m}_{a}$ can be given as a nonlinear function of the manifold pressure $p_{m}$ and engine speed $N$ such that

$$
\dot{m}_{a}\left(p_{m}, N\right)=\sqrt{\frac{T_{m}}{T_{a}}} \frac{V_{d}}{120 R T_{m}} \eta_{v o l}\left(p_{m}, N\right) p_{m} N
$$

where $V_{d}$ is the engine displacement and $\eta_{v o l}$ is the volumetric efficiency.

\section{Fuel Injection Model}

The fuel jet from the fuel injector is mixed with the air stream and some will be deposited on the walls of the intake manifold. This is known as the "wall-wetting" phenomenon for PFI engines, the final fuel flow rate $\dot{m}_{f}$ is the sum of the fuel puddle flow rate $\dot{m}_{f p e}$ and the fuel vapour flow rate $\dot{m}_{f v e}$ entering the combustion chamber

$$
\dot{m}_{f}=\dot{m}_{f p e}+\dot{m}_{f v e}=m_{f p} / \tau_{p}+m_{f v} / \tau_{v}
$$

where $\tau_{p}$ and $\tau_{v}$ are the characteristic manifold time constant for the puddle $m_{f p}$ and vapour $m_{f v}$ fuel mass, respectively. Their dynamics can be taken as a set of two first-order processes with time constant $\tau$ as

$$
\left\{\begin{array}{c}
\dot{m}_{f p}=\chi \dot{m}_{f i}-(1 / \tau) m_{f p}-\dot{m}_{f p e} \\
\dot{m}_{f v}=(1-\chi) \dot{m}_{f i}+(1 / \tau) m_{f p}-\dot{m}_{f v e}
\end{array}\right.
$$

FIGURE 5 Fuel injection process for a Port Fuel-Injected $(\mathrm{PFI})$ engine. The effect from the fuel puddles on the final fuel flow are illustrated.

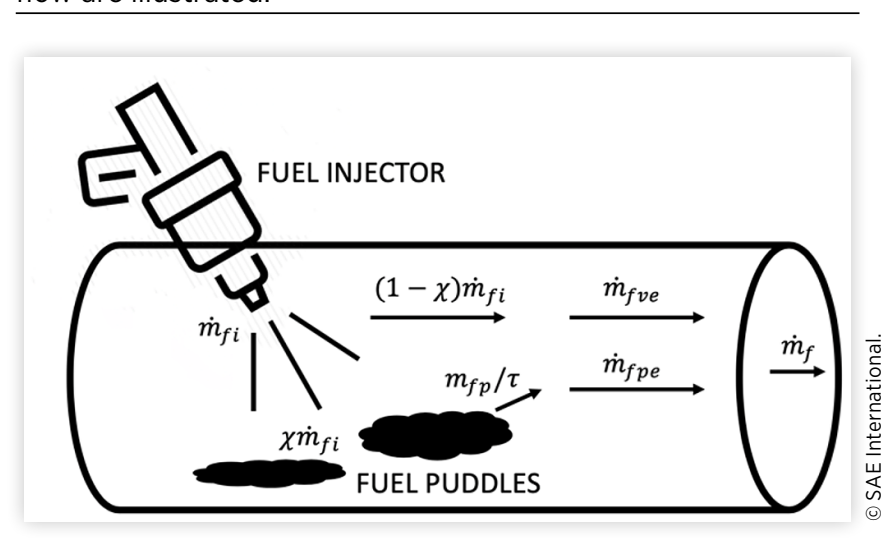

where $\dot{m}_{f i}$ is the injected fuel flow rate (i.e. the control command for the fuel injector), $\chi$ is the fraction of the fuel jet that deposits on the manifold wall as fuel puddles. It should be noted that the fuel injection model (6)(7) is perceived to be more accurate compared to our previous model in [18] since it considers the effect of the Couette flow (the fuel puddle flow $\left.\dot{m}_{f p e}\right)$ entering the chamber. Figure 5 illustrates the fuel injection process for a PFI engine.

\section{Combustion Model}

The combustion characteristics can be modelled in terms of the engine indicated torque $\tau_{\text {ind }}$ using a heat release approach, where the total power created by heat release during combustion is subject to the actual burnt fuel mass flow rate $\dot{m}_{f b}$. A significant feature in the combustion dynamics of Wankel engines is the leakage and crevice volume. The leakage past the apex and side seals must be considered when evaluating the combustion performance [19]. An example of crevice volume and leakage flow is described in Figure 6. The actual burnt fuel fow $\dot{m}_{f b}[\underline{2}$ ] can be modelled as

$$
\dot{m}_{f b}=\frac{1}{\lambda+1}\left(\dot{m}_{a}+\dot{m}_{f}-\dot{m}_{\text {leakage }}-\frac{\dot{p}_{b}}{p_{b}} m_{\text {crevice }}\right)
$$

where $\dot{m}_{\text {leakage }}$ and $m_{\text {crevice }}$ denote the leakage rate and crevice mass of the air-fuel mixture, $p_{b}$ is the chamber pressure, and $\lambda=\dot{m}_{a} / \dot{m}_{f}$ is the air-fuel ratio, of which the stoichiometric value is $\lambda_{d}=14.7$ for petrol.

The indicated torque $\tau_{\text {ind }}$ [7] can be determined as

$$
\tau_{\text {ind }}=H_{u} \frac{\eta_{t h}\left(N, p_{m}, \theta_{S A}, \lambda\right) \dot{m}_{f b}}{N}
$$

where $H_{u}$ is the fuel energy constant and $\eta_{t h}$ is a nonlinear function of the engine speed $N$, the intake manifold pressure $p_{m}$, the spark advance angle $\theta_{S A}$, and the air-fuel ratio $\lambda$. 
FIGURE 6 A schematic of crevice volume and leakage gas flow in a Wankel rotary engine [2].

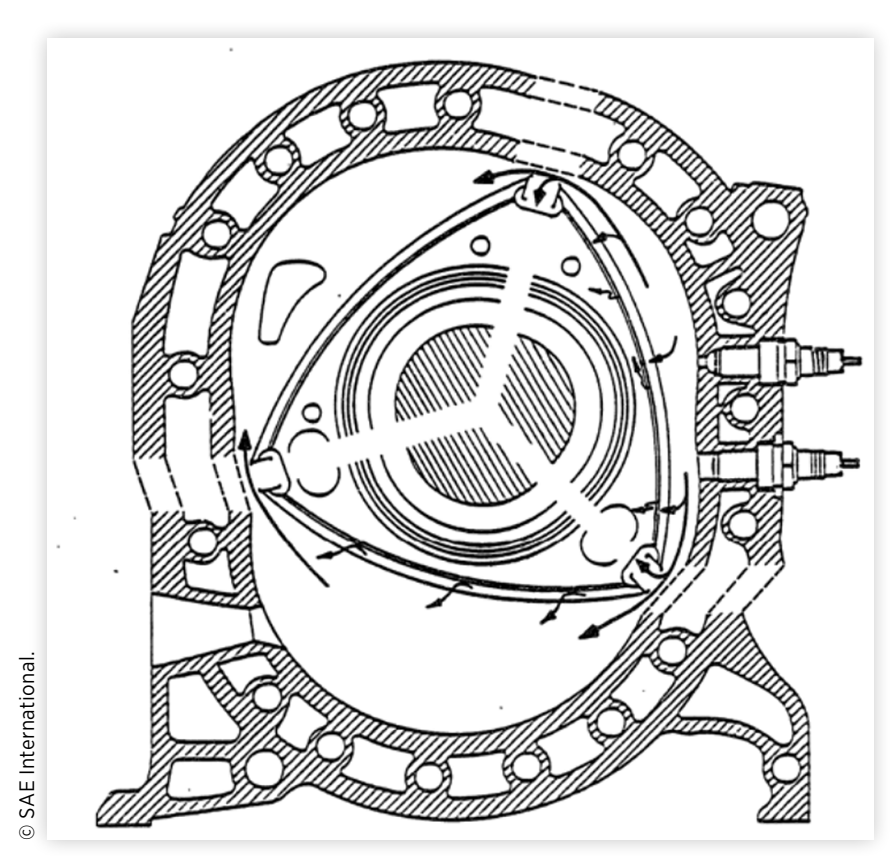

\section{Eccentric Shaft Model}

The eccentric shaft dynamics can be written using Newton's second law as

$$
\dot{J N}=\tau_{\text {ind }}-\tau_{\text {friction }}-\tau_{\text {load }}
$$

where $J$ is the scaled engine moment of inertia, $\tau_{\text {fric }}$ and $\tau_{\text {load }}$ refer to the friction and the load torque, respectively.

An MVEM simulator for the AIE 225CS Wankel engine is established in Matlab/Simulink. The model is verified with the experimental data sets and the fuel injection model is integrated with a nonlinear observer-based air-fuel ratio controller (see our previous work []ㅡ for details). The load torque in the simulator is a user-defined function of the engine speed. Figure 7 outlines the block diagram of the MVEM simulator. Figure 8 shows the throttle profile and the other corresponding signals generated by the MVEM simulator.

FIGURE 7 The block diagram of the MVEM simulator for the Wankel engine. The simulator consists of seven major blocks for 1) throttle angle profile; 2) throttle dynamics; 3) intake manifold dynamics; 4) fuel injection dynamics; 5) combustion dynamics; 6) eccentric shaft dynamics; and 7) load profile.

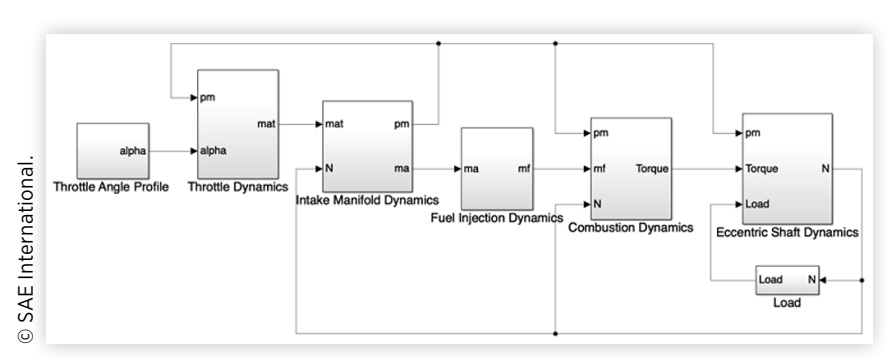

FIGURE 8 Engine dynamic responses generated by the MVEM simulator for a given throttle profile, which includes the intake manifold pressure, the intake manifold temperature, the engine speed, the engine torque, the air-fuel ratio.

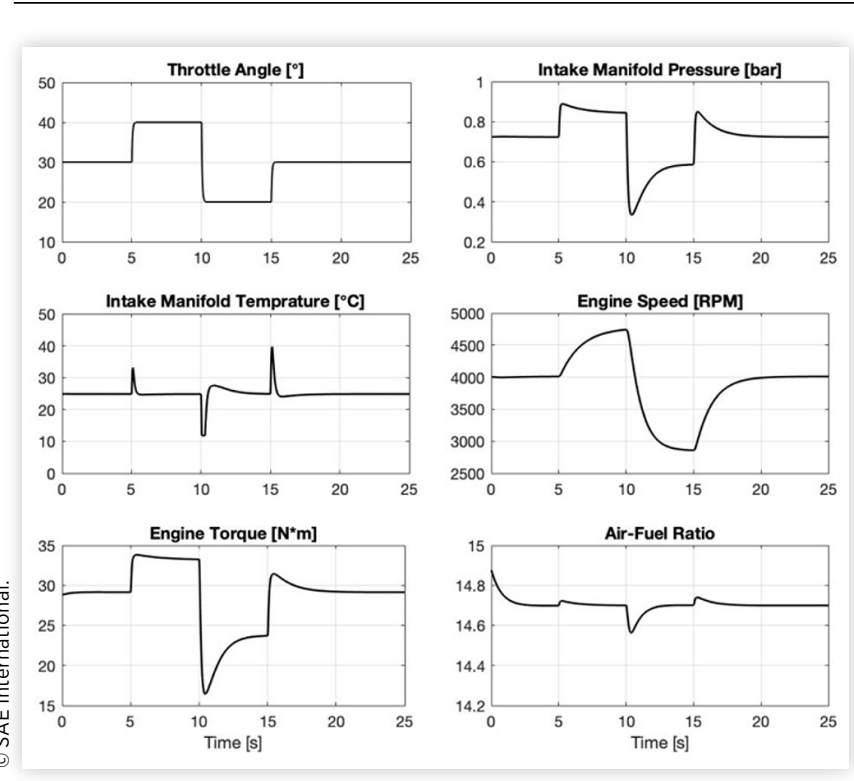

\section{State Space Realisation}

The MVEM consists of several one or more $n$-th order differential equations mixed with empirical static maps to model the inherently nonlinear and coupled dynamics of the engine. In modern control engineering, it is common to develop a more compact model, compared to the MVEM, that uses state variables to describe the system by a set of first-order differential equations. This is known as State-Space (SS) modelling. To leverage the previous results, we can first convert the MVEM into a nonlinear SS representation, then derive a linear SS model via linearisation techniques around a nominal operating point.

\section{Nonlinear State Space Model}

Generally, the model equations are given by

$$
\left\{\begin{array}{l}
\dot{x}=f(x, u, w) \\
y=h(x, u)
\end{array}\right.
$$

where $x \in \mathbb{R}^{n}, w \in \mathbb{R}^{l}$, and $y \in \mathbb{R}^{r}$ represent the state, control input, disturbance, and output vectors, respectively; $f(x, u, w)$, $h(x, u)$ are the nonlinear functions that lumps the MVEM together. We define the state vector from the MVEM for the Wankel engines as

$$
x=\left[\begin{array}{l}
p_{m} \\
T_{m} \\
N \\
m_{f p} \\
m_{f v}
\end{array}\right] \text { intake } \begin{aligned}
& \text { intake manifol puddle mass } \\
& \text { fuel vapour mass }
\end{aligned} \quad n=5
$$


with the control input, disturbance, and output as

$$
\begin{gathered}
u=\left[\begin{array}{c}
\alpha \\
\dot{m}_{f i} \\
\theta_{S A}
\end{array}\right] \begin{array}{l}
\text { throttle angle } \\
\text { injected fuel flow rate } \\
\text { spark advance angle }
\end{array} \\
w=\tau_{\text {load }} \quad \text { load torque } \\
\text { le }
\end{gathered}
$$

$y=\left[\begin{array}{c}\tau_{\text {ind }} \\ \dot{m}_{f} \\ \dot{m}_{a}\end{array}\right] \begin{aligned} & \text { indicated torque } \\ & \text { fuel flow rate entering the chamber } \\ & \text { air flow rate entering the chamber }\end{aligned} \quad r=3$

\section{Linearisation}

We linearise the SS model (11) around the nominal operating point shown in Table 2. The operator $\delta$ denotes the new variable centred about the operating point, e.g., $\delta x(t)=x(t)-x^{0}$. For the throttle body model, we can write $\delta \dot{m}_{a t}$ from $\underline{(1)(2)}$ by taking partial derivatives with respect to $\alpha$ and $p_{m}$ as

$$
\begin{aligned}
& \delta \dot{m}_{a t}=m_{a t 1} \frac{p_{a}}{\sqrt{T_{a}}}\left[\operatorname{PRI}\left(p_{m}^{0}\right) \frac{\partial T C}{\partial \alpha} \delta \alpha+T C\left(\alpha^{0}\right) \frac{\partial P R I}{\partial p_{m}} \partial p_{m}\right] \\
& =c_{11} \delta \alpha+c_{12} \delta p_{m}
\end{aligned}
$$

with constants $c_{11}$ and $c_{12}$.

In the intake manifold model, for $\underline{(5)}$, taking partial derivatives with respect to $p_{m}$ and $N$ for $\delta \dot{m}_{a}$ yields

with constants $c_{21}$ and $c_{22}$. Similarly, we can write for $\delta \dot{T}_{m}$ and $\delta \dot{p}_{m}$ based on (3)(4) as

$$
\begin{gathered}
\delta \dot{T}_{m}=\frac{\partial \dot{T}_{m}}{\partial T_{m}} \delta T_{m}+\frac{\partial \dot{T}_{m}}{\partial p_{m}} \delta p_{m}+\frac{\partial \dot{T}_{m}}{\partial N} \delta N \\
=c_{31} \delta T_{m}+c_{32} \delta p_{m}+c_{33} \delta N \\
\delta \dot{p}_{m}=\frac{\kappa R}{V_{m}}\left(c_{12} T_{a}-\frac{\partial \dot{m}_{a} T_{m}+\dot{m}_{a} \partial T_{m}}{\partial p_{m}}\right) \delta p_{m} \\
+\frac{c_{11} \kappa R}{V_{m}} \delta \alpha-\frac{\kappa R}{V_{m}} \frac{\left(\partial \dot{m}_{a} T_{m}+\dot{m}_{a} \partial T_{m}\right)}{\partial n} \delta N \\
=c_{41} \delta p_{m}+c_{42} \delta \alpha+c_{43} \delta N+c_{44} \delta T_{m}
\end{gathered}
$$

\begin{tabular}{|c|c|c|}
\hline Engine Variable & Symbol & $\begin{array}{l}\text { Nominal } \\
\text { Operating Point }\end{array}$ \\
\hline Throttle Angle & $\alpha^{0}$ & $30\left[^{\circ}\right]$ \\
\hline Engine Torque & $\tau_{\text {ind }}^{0}$ & $30[\mathrm{Nm}]$ \\
\hline Engine Speed & $N^{0}$ & 4000 [RPM] \\
\hline Intake Manifold Temperature & $T_{m}^{0}$ & $25\left[{ }^{\circ} \mathrm{C}\right]$ \\
\hline Intake Manifold Pressure & $p_{m}^{0}$ & 0.7 [bar] \\
\hline Spark Advance Angle & $\theta_{S A}^{0}$ & $18\left[^{\circ}\right]$ \\
\hline Air-Fuel Ratio & $\lambda^{0}$ & $14.7: 1$ \\
\hline
\end{tabular}

TABLE 2 Nominal operating point chosen for engine SS model linearisation. with constants $c_{31}, c_{32}, c_{33}, c_{41}, c_{42}, c_{43}$, and $c_{44}$.

For fuel puddles dynamics, substituting $(6)$ into $\underline{(7)}$ gives

$$
\begin{gathered}
\delta \dot{m}_{f p}=\chi \delta \dot{m}_{f i}-\left(1 / \tau+1 / \tau_{p}\right) \delta m_{f p} \\
\delta \dot{m}_{f v}=(1-\chi) \delta \dot{m}_{f i}+(1 / \tau) \delta m_{f p}-\left(1 / \tau_{m}\right) \delta m_{f v}
\end{gathered}
$$

It is reasonable to assume the leakage and crevice volume is negligible for the linearisation, i.e., $\dot{m}_{f} \approx \dot{m}_{f b}$ for complete combustion. Thus, we can write $\delta \dot{N}$ based on $\underline{(9)(10)}$ as

$$
\begin{aligned}
& \delta \dot{N}= \frac{1}{J} \frac{\partial\left(\tau_{\text {ind }}-\tau_{\text {friction }}\right)}{\partial N} \delta N+\frac{1}{J} \frac{\partial\left(\tau_{\text {ind }}-\tau_{\text {friction }}\right)}{\partial p_{m}} \delta p_{m} \\
&+\frac{1}{J} \frac{\partial\left(\tau_{\text {ind }}\right)}{\partial \theta_{S A}} \delta \theta_{S A}+\frac{1}{J} \frac{\partial\left(\tau_{\text {ind }}\right)}{\partial \lambda} \delta \lambda+\frac{1}{J} \frac{\partial\left(\tau_{\text {ind }}\right)}{\partial \dot{m}_{f}} \delta \dot{m}_{f} \\
&-\frac{1}{J} \delta \tau_{\text {load }} \\
&=c_{51} \delta N+c_{52} \delta p_{m}+c_{53} \delta \theta_{S A}+c_{54} \delta \lambda+c_{55} \delta \dot{m}_{f}-\frac{1}{J} \delta \tau_{\text {load }}
\end{aligned}
$$

with constants $c_{51}, c_{52}, c_{53}, c_{54}$ and $c_{55}$ are constants. It should be noted that the term $c_{54} \delta \lambda \approx 0$ as the air-fuel ratio is closely regulated around a desired constant, e.g. the stoichiometric value.

Thus, we can determine the linear SS model for the nominal operating point shown in Table 2 based on the above derivation as follows.

$$
\left\{\begin{array}{c}
\delta \dot{x}=A \delta x+B \delta u+E \delta w \\
\delta y=C \delta x+D \delta u
\end{array}\right.
$$

with the matrices $A, B, C, D$, and $E$ as

$$
\begin{aligned}
A & =\left[\begin{array}{lllll}
c_{41} & c_{44} & c_{43} & 0 & 0 \\
c_{32} & c_{31} & c_{33} & 0 & 0 \\
c_{52} & 0 & c_{51} & c_{55} / \tau_{p} & -c_{55} / \tau_{m} \\
0 & 0 & 0 & \left(\tau+\tau_{p}\right) / \tau_{p} & 0 \\
0 & 0 & 0 & 1 / \tau & -1 / \tau_{m}
\end{array}\right] \\
B & =\left[\begin{array}{lll}
c_{42} & 0 & 0 \\
0 & 0 & 0 \\
0 & 1 & c_{53} \\
0 & \chi & 0 \\
0 & 1-\chi & 0
\end{array}\right]
\end{aligned}
$$$$
C=\left[\begin{array}{lllll}
c_{52} J & 0 & c_{51} J & c_{55} J / \tau_{p} & -c_{55} J / \tau_{m} \\
0 & 0 & 0 & 1 / \tau_{p} & -1 / \tau_{m} \\
c_{21} & 0 & c_{22} & 0 & 0
\end{array}\right]
$$$$
D=\left[\begin{array}{lll}
0 & c_{53} J & 0 \\
0 & 1 & 0 \\
0 & 0 & 0
\end{array}\right]
$$$$
E=\left[\begin{array}{llllll}
0 & 0 & 1 / J & 0 & 0
\end{array}\right]^{T}
$$ 


\section{Neural Networks}

Engine dynamics are inherently nonlinear and highly coupled. The MVEM and the SS models shown in the previous sections are essentially developed on the basis of physical principles. One can see them as grey-box models that combine a partial theoretical structure and some unknown parameters derived from data. These models observe the engine dynamics with a reasonable level of accuracy, where some physical effects are, however, not directly described and still need hand-tuned correction maps due to nonlinearity. In contrast with grey-box models, we here investigate a powerful tool, artificial Neural Networks (NN), which is one of the black-box modelling techniques and has been widely used in various engineering branches. NN have been proven to be useful for modelling nonlinear dynamic systems and can often achieve distinctly high accuracy.

In this section, we study different classes of $\mathrm{NN}$ with different configurations:

- Multi-Layer Perceptron (MLP) feedforward network:

- Elman recurrent network

- Nonlinear AutoRegressive with eXogenous inputs (NARX) recurrent network

and apply them to engine dynamics modelling using purely input and output data without any a priori knowledge of its internal workings.

\section{Multi-Layer Perceptron (MLP) Neural Network}

We start with the classical type of NN known as Multi-Layer Perceptron (MLP). An MLP is a class of feedforward NN that consists of at least three layers of neurons: an input layer, one or more hidden layers, and an output layer. The input data $U(t) \in \mathbb{R}^{p}$ are propagated from the input layer to the output layer, through the hidden layers, to generate the output signals $\hat{Y}(t) \in \mathbb{R}^{q}$ that will track the reference output data $Y(t) \in \mathbb{R}^{q}$. Each layer of the MLP network are composed of some nonlinearly-activating nodes (neurons) that are fully connected and work in parallel in order to create a flow of information. Each neuron can be seen as Multi-Input, Single-Output (MISO) computing unit where the output $h$ is calculated by processing the weighted sum of the inputs $u$ with bias terms using a transfer function (i.e., an activation function $\varphi$ ). For MLP networks, especially in machine learning community, the logistic sigmoid function $\sigma(x)=1 /\left(1+e^{-x}\right)$ and the hyperbolic tangent function $\tanh (x)=\left(e^{\mathrm{x}}-e^{-x}\right) /\left(e^{\mathrm{x}}+e^{-x}\right)$ are commonly chosen as the activation function. Other popular choices such as the Rectified Linear Unit (ReLU) is frequently used for deep learning problems. For the engine dynamics modelling problem, we select the hyperbolic tangent sigmoid function

$$
\operatorname{transig}(x)=2 /\left(1+e^{-2 x}\right)-1
$$

as the activation function. This is mathematically equivalent to $\tanh (x)$ but proved to be faster when training the network [21]. Thus, the output $h$ of a neuron can be simply expressed as

$$
h_{k}^{\ell}=\varphi_{k}\left(\sum_{j=1}^{N o P} w_{k j}^{\ell} u_{j}+b_{k}^{\ell}\right)
$$

where the subscript $k$ and the superscript $\ell$ denote the $k$-th neuron in the $\ell$-th hidden layer; the subscript $j$ denote the $j$-th neuron in the previous layer; $\varphi(x)$ is the activation function; $N o P$ is the number of the neurons the previous layer; $w$ and $b$ are the weight and bias of a neuron, respectively.

A computational structure such as an MLP network should be able to learn and generalise an input-output mapping from a set of training examples (the input and output data). The proper values of the network weights $w$ and bias terms $b$ can be found via a learning procedure where a cost function is minimised. Figure 9 shows the conceptual architectural graph of a three-layer MLP. A detailed description of $\mathrm{NN}$ approach is beyond the scope of the paper. Readers are referred to [22] for a comprehensive analysis of artificial NN.

In this paper, we assess the intake manifold pressure and engine torque as the main outputs for MLP network design. In some literature [16], it is noted that emissions such as $\mathrm{NO}_{\mathrm{x}}$ or CO are also chosen as the MLP network output. Here we focus on the pressure and torque as they are the primary variables in engine calibration and control. As shown in the MVEM section, the engine torque is a highly nonlinear function of the engine speed, intake manifold pressure, spark advance, air-fuel ratio, fuel flow rate, etc. In order to investigate the potentiality of the $\mathrm{NN}$ to simulate the main features of the engine dynamics, we select the measurable input and output vectors for the MLP network as follows

$$
\begin{aligned}
U & =\left[\begin{array}{l}
\alpha \\
N \\
\lambda \\
\theta_{S A} \\
\dot{m}_{f i}
\end{array}\right] \begin{array}{l}
\text { throttleangle } \\
\text { engine speed } \\
\text { air }- \text { fuel ratio } \\
\text { spark advance angle fuel rate }
\end{array} \quad p=5 \\
Y & =\left[\begin{array}{c}
p_{m} \\
\tau_{\text {ind }}
\end{array}\right] \text { intake pressure } \\
\text { indicated torque } & q=2
\end{aligned}
$$

Different number of neurons in the hidden layer $(k)$ and number of hidden layers $(\ell)$ can be adjusted to fulfil the purpose. These are often referred as "hyperparameters" in the machine learning community. One needs to specify these values for faster training and less overfitting. Figure 10 shows

\section{FIGURE 9 The feedforward architecture of a three-layer} MLP network.

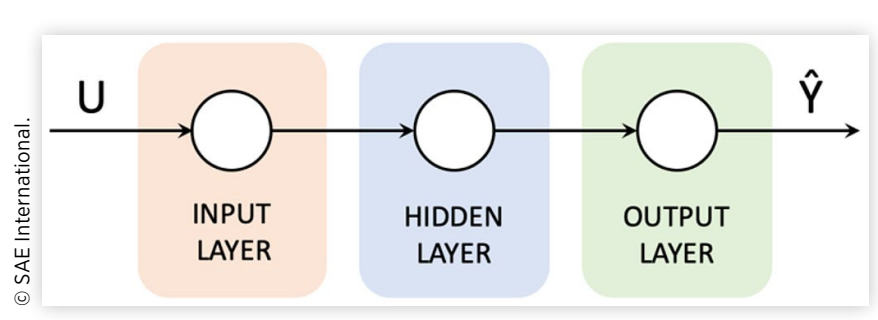


FIGURE 10 The feedforward MLP network configuration for the Wankel engine (with 7 neurons in the hidden layer).

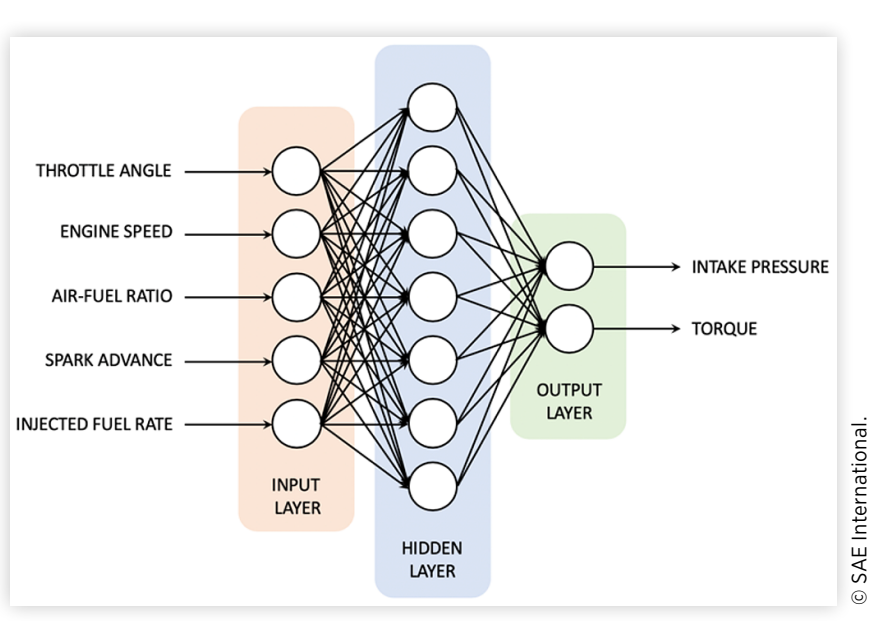

an MLP network with 7 neurons in the hidden layer for the Wankel engine modelling.

\section{Recurrent Neural Networks}

The MLP described in the previous section is an NN with traditional feedforward architecture, where incoming data propagates in a single direction from the input layer to the output layer. Here we introduce a different type of NN named Recurrent Neural Networks (RNN) by considering feedback connections among neurons. The feedback can induce a dynamical effect into the computing units (neurons) by a local memory process. We investigate the RNN and its application on the engine modelling in terms of different topology.

Elman Recurrent Neural Network One of the most basic architectures of RNN is the Elman network, also known as the "Simple RNN". Very similar to the MLP network, the Elman network can be divided into an input layer, one or more hidden layers and an output layer. While the input and output layers are characterised by feedforward connections, the hidden layer contains recurrent connections embedded with time-delay elements. The current input and past network state are combined and processed by the neurons in the hidden layer. The output $h$ of a neuron in the hidden layer can be written as

$$
\begin{aligned}
h_{k}^{\ell}(t)= & \varphi_{k}\left(\sum _ { j = 1 } ^ { N o P } \left(w_{k_{0} j}^{\ell} u_{j}(t)+w_{k_{1} j}^{\ell} h_{j}(t-1)+\ldots\right.\right. \\
& \left.\left.+w_{k_{n} j}^{\ell} h_{j}\left(t-n_{u}\right)+b_{k}^{\ell}\right)\right)
\end{aligned}
$$

where $n_{u}$ is the user-defined finite (often small) number of time delays. The other notations are the same as (25) in the MLP network. Figure 11 shows the recurrent architecture of a threelayer Elman network.

Nonlinear AutoRegressive with eXogenous Inputs (NARX) Recurrent Neural Network Originally, Nonlinear AutoRegressive with eXogenous inputs (NARX) is a commonly-used method in time series modelling and
FIGURE 11 The recurrent architecture of a three-layer Elman network. The red arrow denotes the feedback connections among the neurons in the hidden layer.

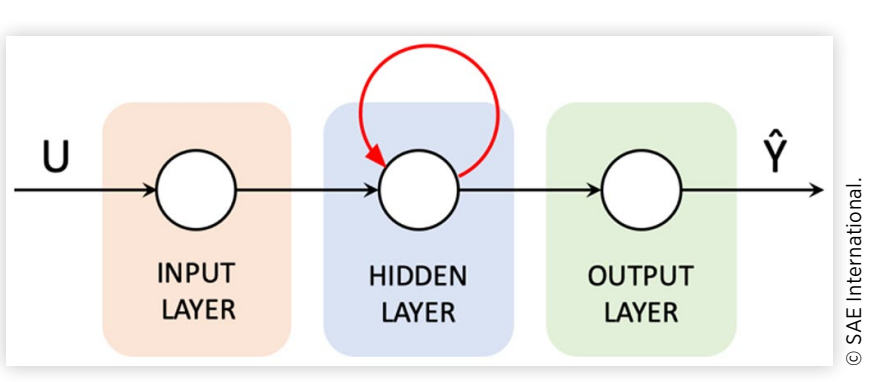

analysis. An NARX model can be seen as an RNN with feedback connections enclosing several layers of the network. Differently from the Elman network, the recurrence in the NARX network is given by the feedback from the output as well. The defining equation for the NARX network can be determined for the output $h$ of a neuron in the hidden layer as

$$
\begin{aligned}
h_{k}^{\ell}(t)= & \varphi_{k}\left(\sum _ { j = 1 } ^ { N o P } \left[w_{k_{0} j}^{\ell} u_{j}(t)+w_{k_{1} j}^{\ell} h_{j}(t-1)+\ldots+w_{k_{n} j}^{\ell} h_{j}\left(t-n_{u}\right)\right.\right. \\
& \left.\left.+w_{k_{1} j}^{\ell} y_{j}(t-1)+\ldots+w_{k_{n} j}^{\ell} y_{j}\left(t-n_{y}\right)+b_{k}^{\ell}\right]\right)
\end{aligned}
$$

where $n_{u}$ and $n_{y}$ are the user-defined finite (often small) number of time delays. The other notations are the same as (27) in the Elman network. Figure 12 shows the recurrent architecture of a three-layer NARX network.

It is worth noting that the NARX network feeds back the delayed signals $h$ and $y$ in parallel. In the engine modelling case, since the engine toque as the actual output signal is measurable and available during the training of the network, one can leverage the actual output to create a series-parallel architecture [23], in which the actual output $Y(t)$ is used instead of feeding back the estimated output $\hat{Y}(t)$. Figure 13 shows the use of the series-parallel architecture for the training of an NARX network.

\section{FIGURE 12 The recurrent architecture of a three-layer} NARX network. The red arrows denote the feedback connections among the neurons in the hidden layer and from the output layer (compared with the Elman network in Figure $x x$ ).

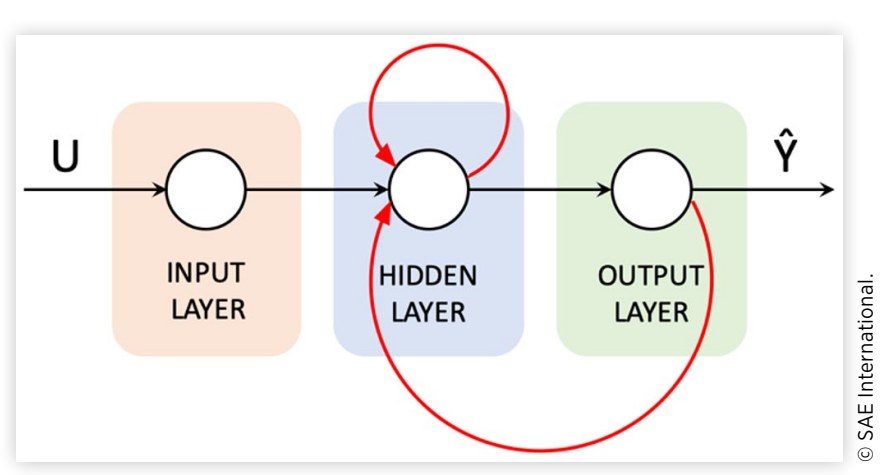


FIGURE 13 The recurrent series-parallel architecture of a three-layer NARX network (Training mode). The red arrows denote the feedback connections among the neurons in the hidden layer and from the actual outputs (compared with the parallel architecture in Figure $\mathrm{xx}$ ).

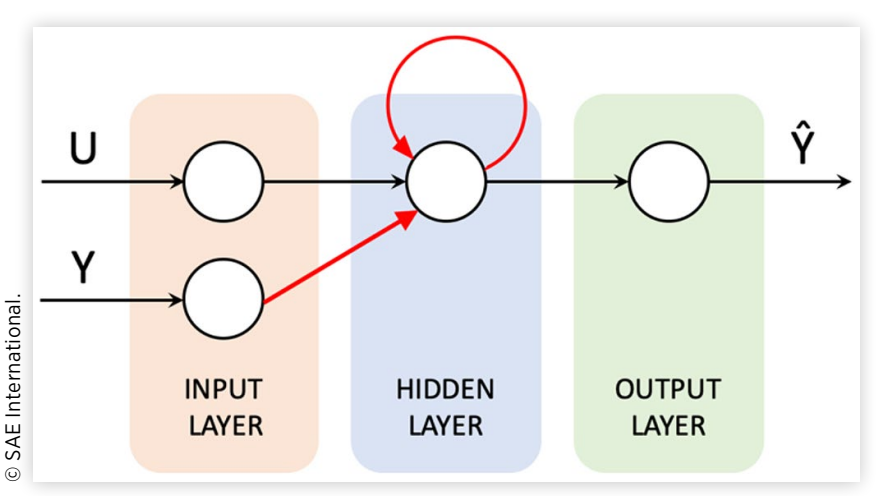

\section{Comparative Results}

In this section, we present the model validation results for the SS model and the NN models. The results are compared and analysed in terms of the fidelity, the applicability, and the model calibration (or NN training) process.

\section{Linear SS Model}

In order to verify the fidelity of the linear SS model, we check the torque response of the SS model against the same throttle angle profile for the MVEM. The throttle sweeps around $30\left[^{\circ}\right]$ with small excursion $\pm 10\left[^{\circ}\right]$. The torque and the intake manifold pressure responses from the two models are shown in Figure 14. It is clear to see the linear behaviour of the SS model against the nonlinearity of the MVEM while both responses follow a similar trend.

It is evident that the linearised model is only valid in a neighbourhood of the nominal operating point. To design a global dynamic control, one can merge together different controls designed for a number of nominal operating points via simple gain scheduling or more sophisticated control techniques such as adaptive control [18].

\section{NN Models}

We use the Levenberg-Marquardt backpropagation algorithm [24] for training the three NN, namely the MLP network, the Elman network and the NARX network. The performance of an NN can be evaluated by using the Mean Squared Error (MSE) and regression analysis. The MSE is the average squared difference between the estimate and the target outputs and the correlation coefficient $R$ is used for the regression analysis. Through multiple trainings with different hyperparameter settings (only one hidden layer for all NN, i.e., $\ell=1$ ), the MSE and the regression $R$ are summarised in Table 3 . There are many rule-of-thumb methods for determining the appropriate number of hidden neurons. Underfitting occurs when there are too few neurons in the hidden layer to adequately detect
FIGURE 14 The intake manifold pressure and the torque responses of the linear SS model and the MVEM around the nominal operating point.
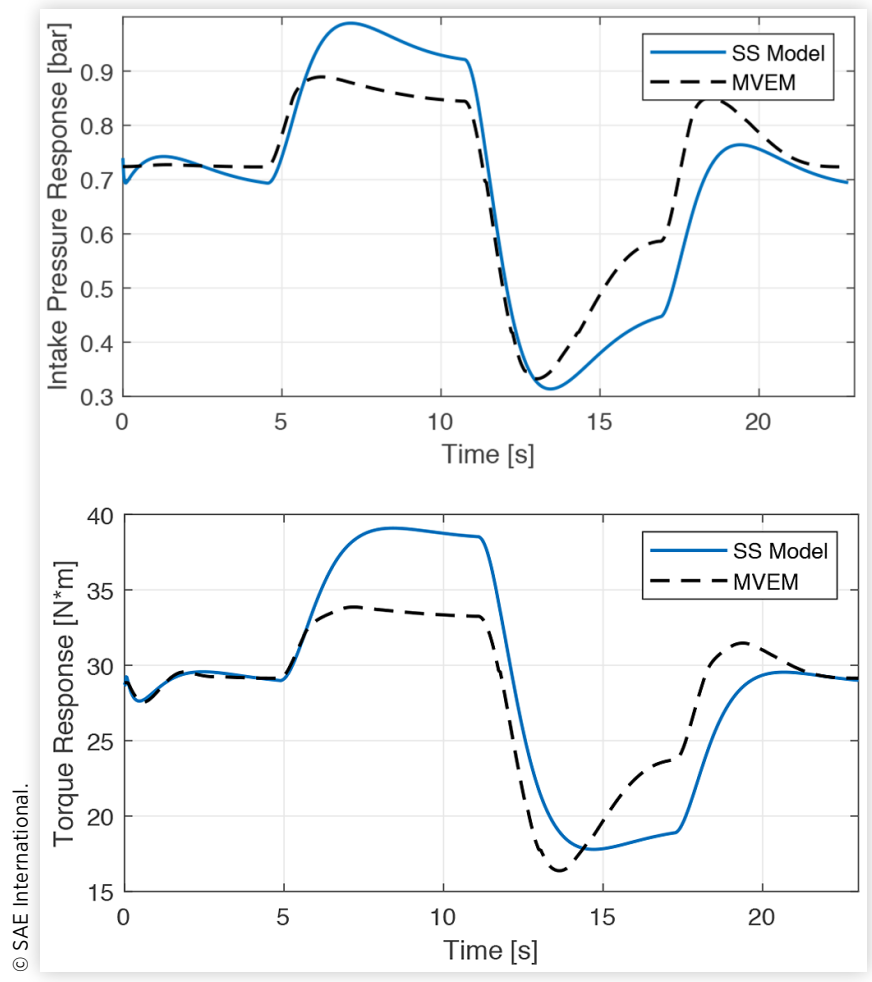

TABLE 3 The MSE and the correlation coefficient R for the three types of NN.

\begin{tabular}{|c|c|c|c|c|c|}
\hline NN & Output & $\begin{array}{l}\text { Number } \\
\text { of } \\
\text { Hidden } \\
\text { Neurons }\end{array}$ & $\begin{array}{l}\text { Number } \\
\text { of Time } \\
\text { Delays }\end{array}$ & MSE & $\mathbf{R}$ \\
\hline \multirow[t]{6}{*}{ MLP } & \multirow{3}{*}{$\begin{array}{l}\text { Intake } \\
\text { Pressure }\end{array}$} & 3 & & 1.45144 & 0.99541 \\
\hline & & 7 & & 0.21168 & 0.99930 \\
\hline & & 10 & & 0.13156 & 0.99957 \\
\hline & \multirow{3}{*}{$\begin{array}{l}\text { Engine } \\
\text { Torque }\end{array}$} & 3 & & 0.27029 & 0.99622 \\
\hline & & 7 & & 0.15540 & 0.99782 \\
\hline & & 10 & & 0.10385 & 0.99880 \\
\hline \multirow[t]{6}{*}{ Elman } & \multirow{3}{*}{$\begin{array}{l}\text { Intake } \\
\text { Pressure }\end{array}$} & 7 & 1 & 0.19126 & 0.99887 \\
\hline & & 7 & 2 & 0.18478 & 0.99938 \\
\hline & & 10 & 2 & 0.12929 & 0.99943 \\
\hline & \multirow{3}{*}{$\begin{array}{l}\text { Engine } \\
\text { Torque }\end{array}$} & 7 & 1 & 0.15738 & 0.99722 \\
\hline & & 7 & 2 & 0.11357 & 0.99850 \\
\hline & & 10 & 2 & 0.10174 & 0.99888 \\
\hline \multirow[t]{6}{*}{ NARX } & \multirow{3}{*}{$\begin{array}{l}\text { Intake } \\
\text { Pressure }\end{array}$} & 7 & $1 ; 1$ & 0.09476 & 0.99968 \\
\hline & & 7 & $2 ; 2$ & 0.08423 & 0.99978 \\
\hline & & 10 & $2 ; 2$ & 0.09077 & 0.99970 \\
\hline & \multirow{3}{*}{$\begin{array}{l}\text { Engine } \\
\text { Torque }\end{array}$} & 7 & $1 ; 1$ & 0.00440 & 0.99994 \\
\hline & & 7 & $2 ; 2$ & 0.00376 & 0.99995 \\
\hline & & 10 & $2 ; 2$ & 0.00369 & 0.99995 \\
\hline
\end{tabular}


the data. On the other hand, too many neurons in the hidden layer may result in overfitting and the increase of the training time. Some exemplar choices of the number of hidden neurons such as 3, 7, 10 are tested as shown in Table 3 . Figure 15 to $\underline{17}$ presents the regression analysis for the three $\mathrm{NN}$ with respect to the outputs, i.e. the intake manifold pressure and the engine torque. The comparative responses for the two outputs are shown in Figure 18 and $\underline{19}$.

FIGURE 15 Regression analysis with respect to the intake manifold pressure and the engine torque for the MLP network with 3 neurons in the hidden layer.

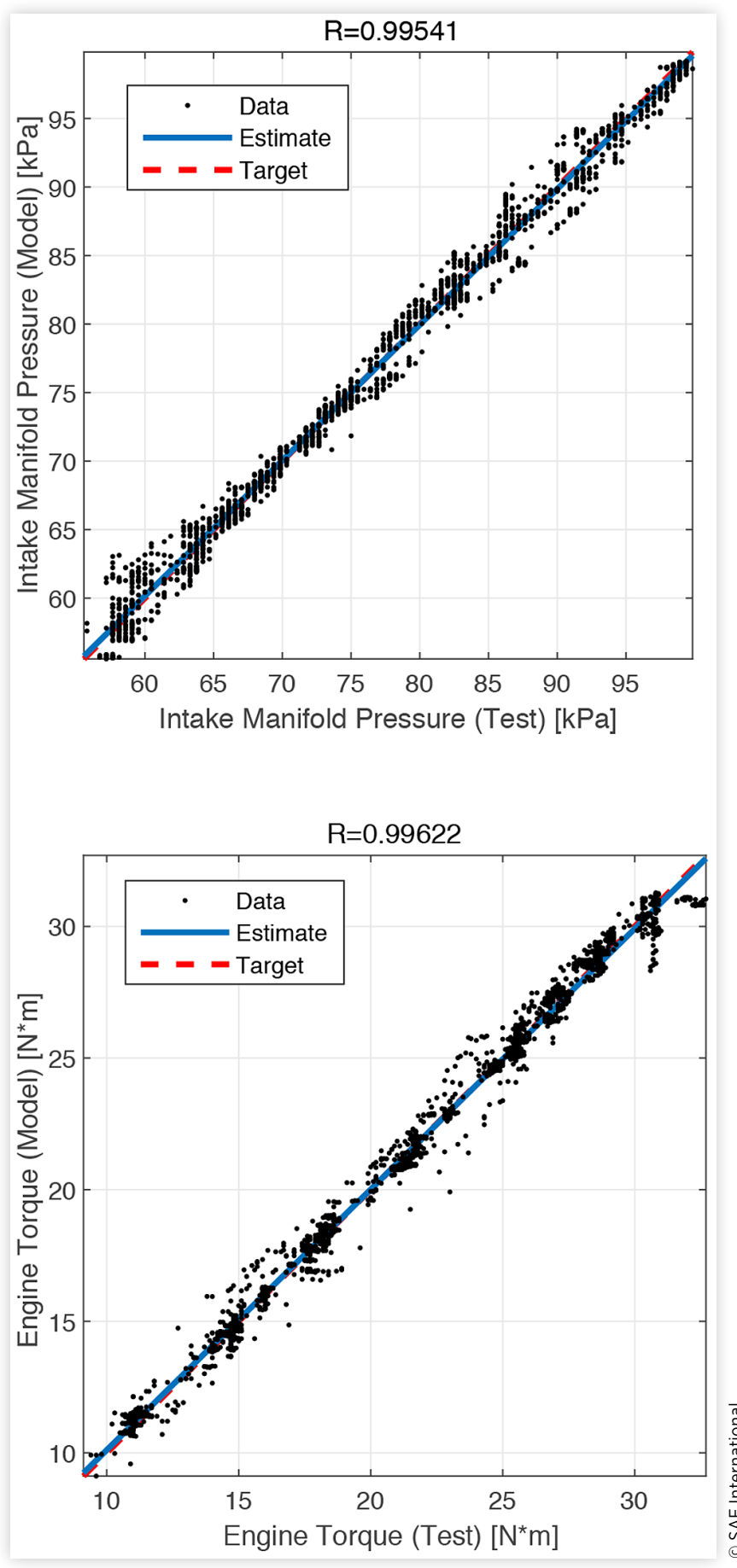

FIGURE 16 Regression analysis with respect to the intake manifold pressure and the engine torque for the Elman network with 10 neurons in the hidden layer and 2 time delays.
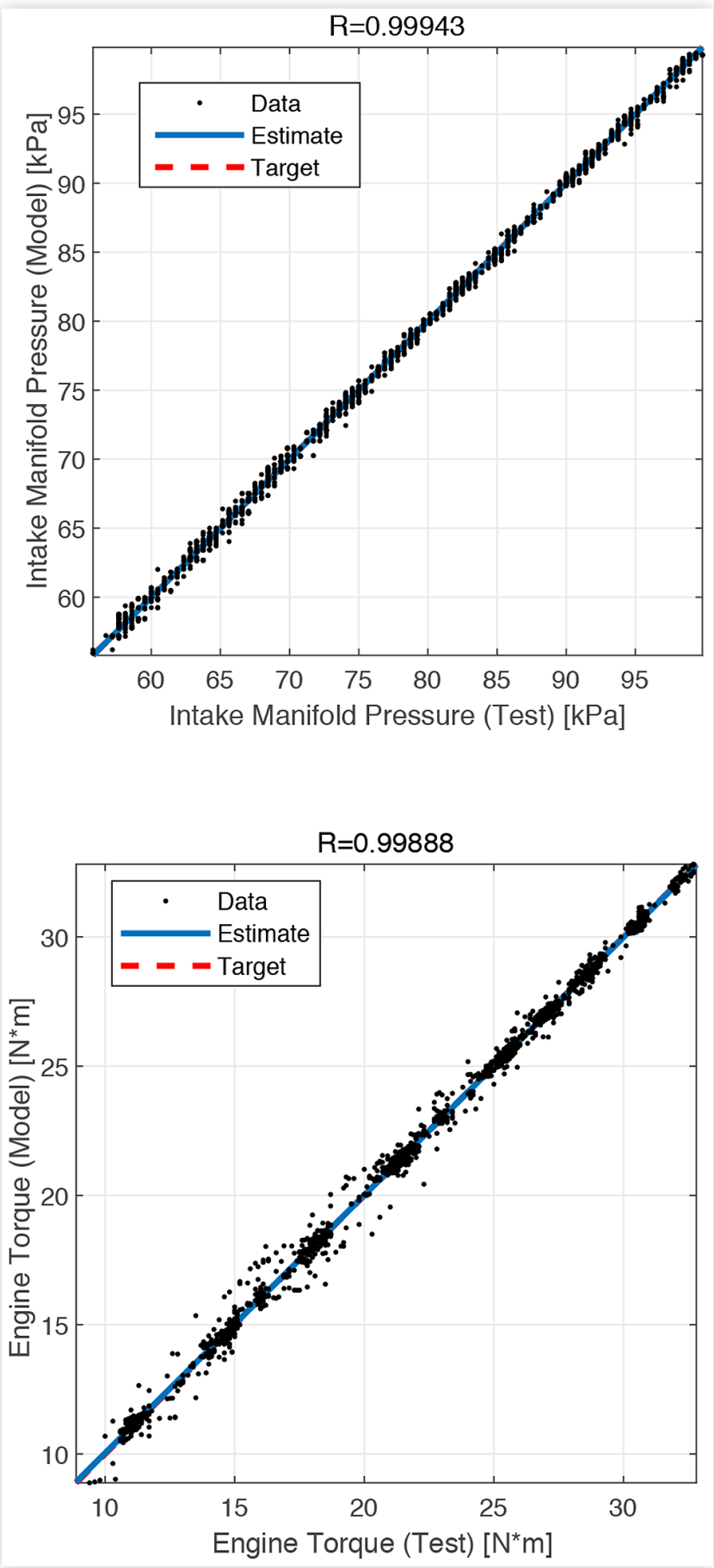

Overall, the three types of $\mathrm{NN}$ are all able to satisfactorily describe the engine dynamics, where the regression values $R$ are all above 0.99 . This result confirms the capability of the $\mathrm{NN}$ in nonlinear dynamic system modelling. In particular, the NARX network demonstrates to be the most accurate architecture for modelling the Wankel engine. The highest accuracy is achieved when the NARX network has 10 neurons in the hidden layer and 2 recurrent time delays. The torque estimation fits exceptionally well with $R=0.99995$. The Elman 
FIGURE 17 Regression analysis with respect to the intake manifold pressure and the engine torque for the MLP network with 7 neurons in the hidden layer and 2 time delays.
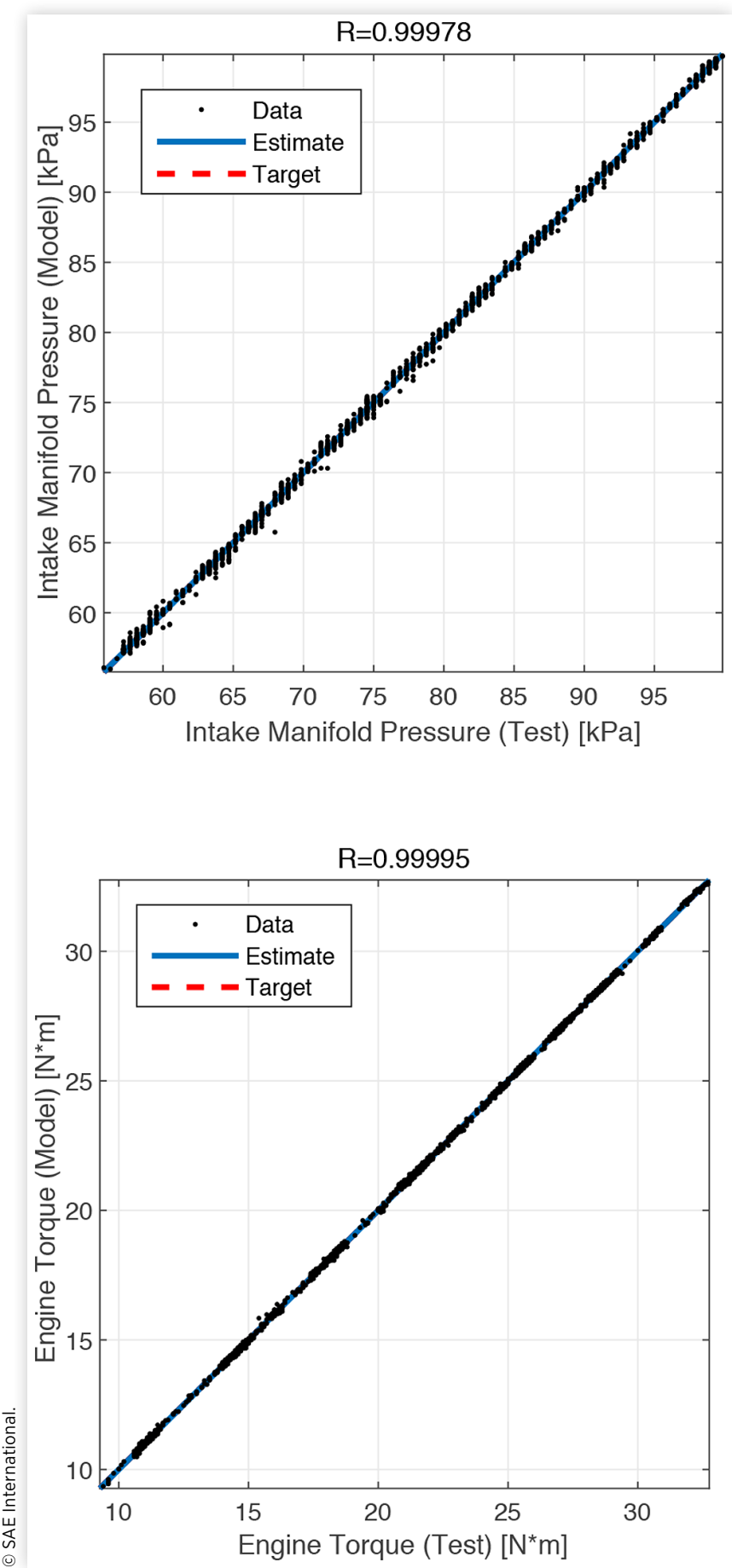

network can reach almost equally the performance comparable with the NARX network, especially when predicting the intake pressure. Compared to the two RNN, the MLP network being a static mapping with only feedforward architecture struggles to achieve the equivalent accuracy and may not guarantee trustworthy dynamic response since no delays are used between the input and output. This is evident in Figure 18, the intake manifold pressure response at around
FIGURE 18 The intake manifold pressure responses for the MLP, Elman, and NARX networks compared with the measured engine test data.

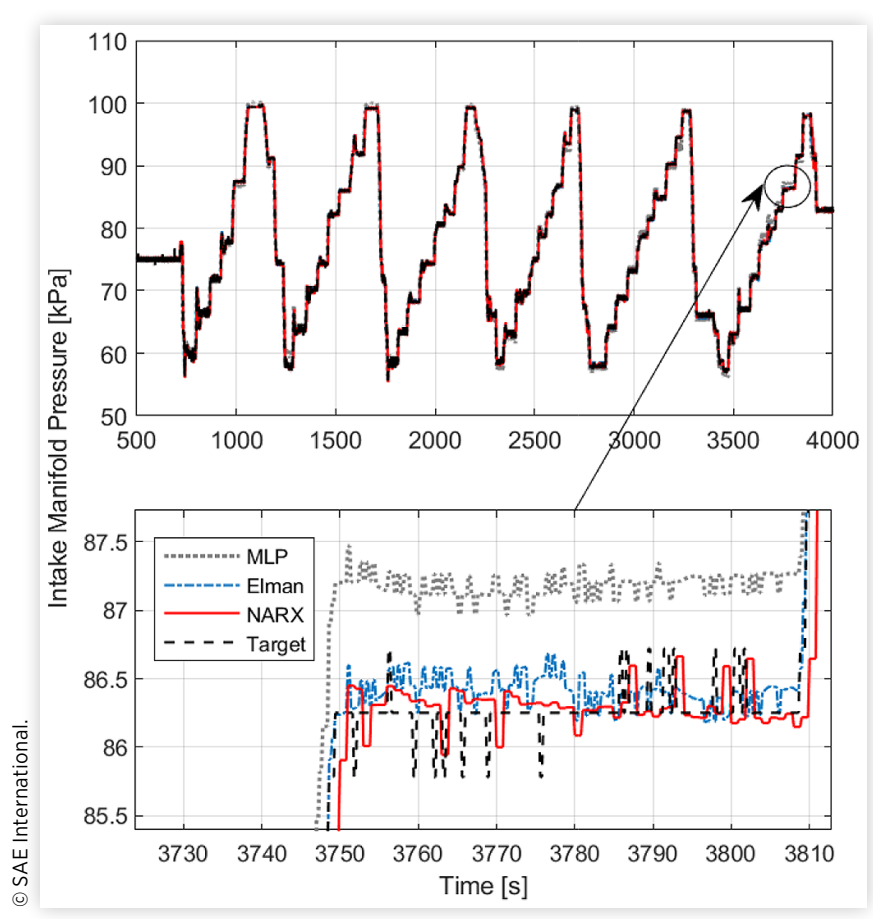

FIGURE 19 The torque responses for the MLP, Elman, and NARX networks compared with the measured engine test data.

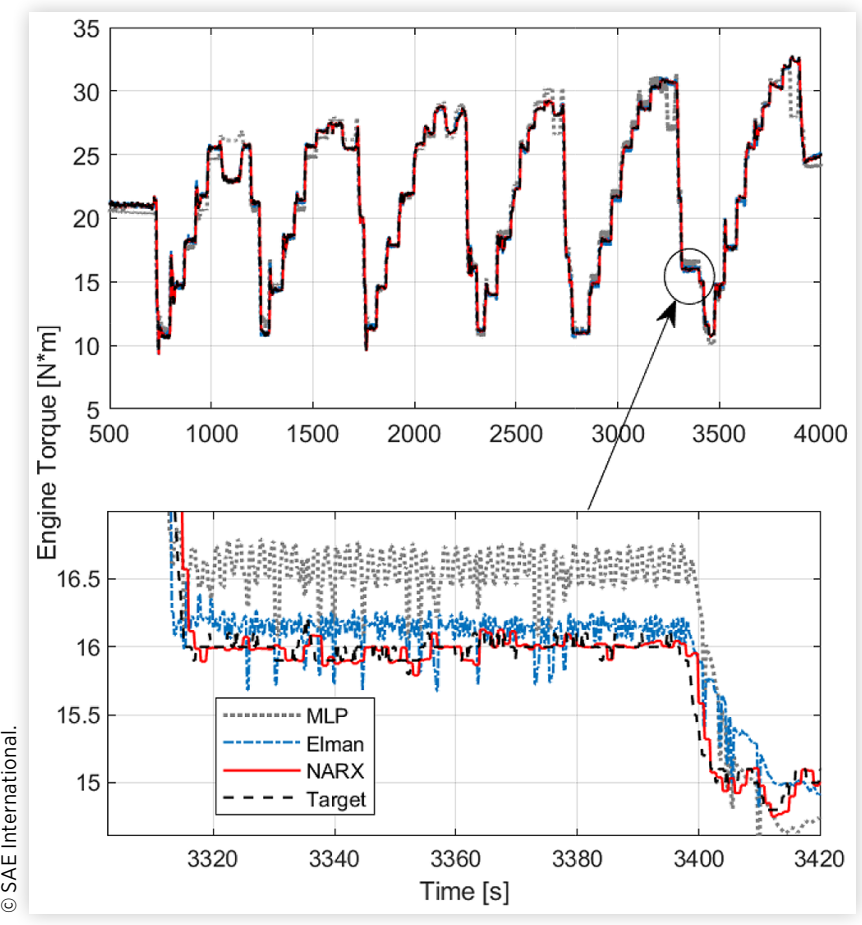

3750s, where one finds that the MLP output transient is leading the target output transient. Such deviation from the realistic response can be ascribed to the lack of feedback mechanism in the MLP. However, it is noted that the training process for the MLP is faster than the other two RNN with 
the same number of hidden neurons since there is no need computing for the time delays. It is interesting to notice that, for this engine modelling task, a network with a limited number of hidden neurons is less prone to overfit on the training data. However, very low number of hidden neurons may lead to inferior modelling accuracy. Furthermore, increasing the number of hidden neurons introduces more complexity and does not guarantee the improvement of accuracy, especially for the RNN with more time delays. The performance is vaguely improved or even dropped slightly when the number of hidden neurons grows from 7 to 10 for both Elman and NARX network. The trade-off between the computational complexity and the model accuracy is needed when implementing the $\mathrm{NN}$ engine model in the control development process.

\section{Model Synthesis and Conclusions}

The three types of mathematical models presented in this paper are 1) the MVEM; 2) the SS model; and 3) the NN model. By using either (or both) physical knowledge or test data, these models are able to describe the Wankel engine dynamics with acceptable accuracy. They are all control-oriented models that have less computational demand and should be able to run faster than the available CFD models due to their simplicity.

For each model: 1) The MVEM model is a state-of-the-art approach for engine dynamics modelling and allows an in-depth study of engine physics and mechanisms. It consists of interconnected subsystems of the engine dynamics which are mostly in the form of nonlinear differential equations or empirical maps, which result in low-level fidelity but fast running speed. 2) The linear SS model characterise the engine dynamics as a set of first-order state equations. It has the simplest form yet the least accuracy since it is only valid in the neighbourhood around a nominal operating point. However, one can always merge together different controls designed for a number of nominal operating points via simple gain scheduling to design a global dynamic control. As a prominent characteristic of modern control theory, an SS model becomes very handy when designing an advanced control system, e.g., via optimal control, robust control, and intelligent control. 3) The NN models are essentially data-driven models via black-box system identification. They are able to predict the dynamic behaviour of the Wankel engine by using the data collected from the engine tests and does not require a priori knowledge of the engine configuration or an understanding of underlying physics. Different network architecture can lead to different levels of performance, but the NN models overall tend to achieve higher accuracy than the MVEM and the SS model. In particular, the NARX network demonstrates the highest performance with acceptable complexity.

In the procedure of control development for the Wankel engine, one can use the SS model for the design phase of a control system for its simplicity and then use the NN model for the validation phase for its accuracy. Another benefit of the NN model can be derived by integrating it into the MVEM.
The thermodynamic process of the combustion model is difficult to characterise and it relies on the static maps for the thermal efficiency in the MVEM (see (9)). Based on the results in this paper, one can easily create an NN model that outputs the engine torque using the measured input signals. This NN model could be used to replace the specific combustion model in the MVEM due to its better predicting capability.

The focus of the future work will include air-fuel ratio control and idle speed control for the Wankel engine using the control-oriented models developed in this paper. A novel adaptive optimal control (reinforcement learning) strategy and its implementation on the ECU will be investigated.

\section{References}

1. Dark, H.E., The Wankel Engine: Introduction \& Guide (Ontario: Fitzhenry \& Whiteside Ltd, 1974).

2. Norman, T.J., "A Performance Model of a Spark Ignition Wankel Engine: Including the Effects of Crevice Volumes", Gas Leakage, and Heat Transfer, Doctoral dissertation, Massachusetts Institute of Technology.

3. Arsie, I., Pianese, C., and Rizzo, G., "Identification of Manifold Two-Phase Fuel Flow Model in a Spark Ignition Engine with Kalman Filter and Least Square Methods," in 7th IEEE Mediterranean Conference on Control \& Systems, 1999, June, 28-30.

4. Peden, M., Turner, M., Turner, J.W.G., and Bailey, N., "Comparison of 1-D Modelling Approcahes for Wankel Engine Performance Simulation and Initial Study of the Direct Injection Limitations," SAE Technical Paper 2018-011452, 2018, https://doi.org/10.4271/2018-01-1452.

5. Chen, A.S., Herrmann, G., Na, J., Turner, M., Vorraro, G. and Brace, C., "Nonlinear Observer-Based Air-Fuel Ratio Control for Port Fuel Injected Wankel Engines". in 2018 UKACC 12th International Conference on Control (CONTROL), (224-229), IEEE, 2018, September, doi. org/10.1109/control.2018.8516842.

6. Vorraro, G., Turner, M., and Turner, J.W., “Testing of a Modern Wankel Rotary Engine-Part I: Experimental Plan, Development of the Software Tools and Measurement Systems," SAE Technical Paper 2019-01-0075, 2019, $\underline{\text { https:// }}$ doi.org/10.4271/2019-01-0075.

7. Hendricks, E. and Luther, J.B., "Model and observer based control of internal combustion engines. In Proceedings of International Workshop on Modeling", Emissions and Control in Automotive Engines (MECA01), September 2001.

8. Hendricks, E., Chevalier, A., Jensen, M., Sorenson, S.C. et al., "Modelling of the Intake Manifold Filling Dynamics," SAE Transactions 122-146, 1996.

9. Ogata, K. and Yang, Y., Modern Control Engineering. Vol. 4 (London, 2002).

10. Cassidy, J., Athans, M., and Lee, W.H., "On the Design of Electronic Automotive Engine Controls Using Linear Quadratic Control Theory," IEEE Transactions on Automatic Control 25(5):901-912, 1980, doi:doi.org/10.1109/cdc.1978.268054.

11. Cook, J.A. and Powell, B.K., "Modeling of an Internal Combustion Engine for Control Analysis," IEEE Control Systems Magazine 8(4):20-26, 1988. 
12. He, Y. and Rutland, C.J., "Application of Artificial Neural Networks in Engine Modelling," International Journal of Engine Research 5(4):281-296, 2004.

13. Ismail, H.M., Ng, H.K., Queck, C.W., and Gan, S., "Artificial Neural Networks Modelling of Engine-Out Responses for a Light-Duty Diesel Engine Fuelled with Biodiesel Blends," Applied Energy 92:769-777, 2012.

14. Nikzadfar, K. and Shamekhi, A.H., "An Extended Mean Value Model (EMVM) for Control-Oriented Modeling of Diesel Engines Transient Performance and Emissions," Fuel 154:275-292, 2015, doi:doi.org/10.1016/j.fuel.2015.03.070.

15. Deng, J., Stobart, R., and Maass, B., "The Applications of Artificial Neural Networks to Engines. In Artificial Neural Networks-Industrial and Control Engineering Applications," (InTechOpen, 2011).

16. Maass, B., Stobart, R., and Deng, J., "Prediction of NOx Emissions of a Heavy Duty Diesel Engine with a NLARX Model," SAE Technical Paper 2009-01-2796, 2009, https:// doi.org/10.4271/2009-01-2796.

17. Ćirović, V., Aleksendrić, D., and Mladenović, D., "Braking Torque Control Using Recurrent Neural Networks," Proceedings of the Institution of Mechanical Engineers, Part D: Journal of Automobile Engineering 226(6):754-766, 2012.

18. Chen, A.S., Na, J., Herrmann, G., Burke, R., and Brace, C., "Adaptive Air-Fuel Ratio Control for Spark Ignition Engines with Time-Varying Parameter Estimation", in 2017 9th International Conference on Modelling, Identification and Control (ICMIC), IEEE, July 2017, 1074-1079, doi.org/10.1109/ icmic.2017.8321616.

19. Sierens, R., Baert, R., Winterbone, D.E., and Baruah, P.C., "A Comprehensive Study of Wankel Engine Performance," SAE Technical Paper $\underline{830332}, 1983$, https://doi. org/10.4271/830332.

20. Danieli, G.A., Keck, J.C., and Heywood, J.B., "Experimental and Theoretical Analysis of Wankel Engine Performance," SAE Technical Paper 780416, 1978, https://doi. org/10.4271/780416.

21. Vogl, T.P., Mangis, J.K., Rigler, A.K., Zink, W.T., and Alkon, D.L., "Accelerating the Convergence of the Back-Propagation Method," Biological Cybernetics 59(4-5):257-263, 1988.

22. Shanmuganathan, S., "Artificial Neural Network Modelling: An Introduction," In: Artificial Neural Network Modelling. (Cham, Springer, 2016), 1-14.

23. Narendra, K.S. and Parthasarathy, K., "Learning Automata Approach to Hierarchical Multiobjective Analysis," IEEE Transactions on Systems, Man, and Cybernetics 21(1):263272, 1991, doi:doi.org/10.1109/21.101158.

24. Hagan, M.T. and Menhaj, M.B., "Training Feedforward Networks with the Marquardt Algorithm," IEEE transactions on Neural Networks 5(6):989-993, 1994, doi:doi. org/10.1109/72.329697.

\section{Contact Information}

\section{Anthony Siming Chen}

$\mathrm{PhD}$ Candidate in Dynamics and Control

Department of Mechanical Engineering

University of Bristol

Bristol BS8 1QU
United Kingdom

anthony.chen@bristol.ac.uk

\section{Guido Herrmann}

Professor of Robotics and Intelligent Control

Department of Electrical and Electronic Engineering

University of Manchester

Manchester M13 9PL

United Kingdom

guido.herrmann@manchester.ac.uk

\section{Stuart Burgess}

Professor of Engineering Design

Department of Mechanical Engineering

University of Bristol

Bristol BS8 1QU

United Kingdom

s.c.burgess@bristol.ac.uk

\section{Chris Brace}

Professor of Automotive Propulsion

Department of Mechanical Engineering

University of Bath

Bath BA2 7AY

United Kingdom

c.j.brace@bath.ac.uk

\section{James Turner}

Professor of Engines and Energy Systems

Department of Mechanical Engineering

University of Bath

Bath BA2 7AY

United Kingdom

j.turner@bath.ac.uk

\section{Acknowledgments}

The authors wish to gratefully thank the Advanced Propulsion Centre (APC) UK for their financial support.

Thanks also go to the ADAPT project partners including the Institute for Advanced Automotive Propulsion Systems (IAAPS), Advanced Innovative Engineering (AIE), General Engine Management Systems (GEMS), Westfield Sportscar, and Saietta.

\section{Definitions/Abbreviations}
AC - Alternating current
CAD - Computer-aided design
CAN - Controller area network
CFD - Computational fluid dynamics
CO - Carbon monoxide
DFI - Direct fuel injection
ECU - Engine control unit
HEV - Hybrid electric vehicles
MIMO - Multi-input, multi-output
MISO - Multi-input, single-output
MLP - Multi-layer perceptron 
MSE - Mean squared error

MVEM - Mean value engine model

NARX - Nonlinear autoregressive with exogenous inputs

NN - Neural networks

$\mathbf{N O}_{\mathbf{x}}$ - Nitrogen oxide

PFI - Port fuel injection

ReLU - Rectified linear unit

RNN - Recurrent neural network

SS - State space

\section{Nomenclatures}

D - Throttle diameter

$\boldsymbol{H}_{u}$ - Fuel energy constant

$J$ - Scaled engine moment of inertia

$\dot{m}_{a}$ - Air mass flow rate into the chamber

$\dot{m}_{a t}$ - Air mass flow rate passing the throttle

$\dot{m}_{f}$ - Fuel mass flow rate into the chamber

$\dot{m}_{f b}$ - Burnt fuel flow rate

$\dot{m}_{f i}$ - Injected fuel flow rate

$\dot{m}_{f p}$ - Fuel puddle mass

$\dot{m}_{f v}$ - Fuel vapour mass

$\boldsymbol{N}$ - Engine speed

$\boldsymbol{p}_{a}$ - Ambient pressure $\boldsymbol{p}_{m}$ - Intake manifold pressure

$\boldsymbol{R}$ - Ideal gas constant

$\boldsymbol{T}_{a}$ - Ambient temperature

$\boldsymbol{T}_{m}$ - Intake manifold temperature

$\boldsymbol{V}_{d}$ - Engine displacement

$V_{m}$ - Intake manifold volume

$\boldsymbol{\alpha}$ - Throttle angle

$\boldsymbol{\kappa}$ - Specific heat capacity

$\boldsymbol{\eta}_{v o l}$ - Volumetric efficiency

$\boldsymbol{\eta}_{t h}$ - Thermal efficiency

$\chi$ - Fuel puddle Fraction

$\lambda$ - Air-fuel ratio

$\boldsymbol{\tau}$ - Fuel puddle time constant

$\boldsymbol{\tau}_{\text {ind }}$ - Indicated torque

$\tau_{\text {load }}$ - Load torque

$\boldsymbol{\theta}_{S A}$ - Spark advance angle

$\boldsymbol{u}$ - Input vector

$\boldsymbol{w}$ - Disturbance vector

$\boldsymbol{x}$ - State vector

$\boldsymbol{y}$ - Output vector

$\boldsymbol{h}$ - Neuron output

$\boldsymbol{w}_{k j}$ - Neuron weight

$\boldsymbol{b}_{k}$ - Neuron bias term

$\boldsymbol{\varphi}$ - Activation function

(c) 2020 SAE International. All rights reserved. No part of this publication may be reproduced, stored in a retrieval system, or transmitted, in any form or by any means, electronic, mechanical, photocopying, recording, or otherwise, without the prior written permission of SAE International. 